\title{
Correction and Remark to "Continuity of the mean values of BMO functions and Calderón-Zygmund properties of certain singular integrals"
}

(Bull. Fac. Sci., Ibaraki Univ., Math., No. 15 (1983), 1-8)

\section{Kôzô YABUTA*}

In the above paper there were some inaccuracies and should be modified as follows:

Page 2. Line $5 \downarrow$ : Add $K(x, y)$ between "function" and "on".

Page 3. Line 1 $\downarrow: \log \frac{b-a}{d-c}$ should be read as $\left(\log \frac{b-a}{d-c}+1\right)$.

Page 3. Line $2 \downarrow$ : $a<c<d<b$ should be read as $a \leqq c<d \leqq b$.

Next we note that the following singular integrals are Calderón-Zygmund singular integrals: Let $A(x)$ be a real valued function with $A^{\prime}(x) \in \operatorname{BMO}(\boldsymbol{R})$ and consider

$$
\begin{aligned}
& T_{1} f(x)=\text { p.v. } \int_{-\infty}^{\infty} \frac{1}{x-y} \exp \left(i \frac{A(x)-A(y)}{x-y}\right) f(y) d y, \text { and } \\
& T_{2} f(x)=\text { p.v. } \int_{-\infty}^{\infty} \frac{f(y) d y}{x-y+i(A(x)-A(y))} .
\end{aligned}
$$

These are singular integrals of Calderon type, related to the Cauchy integral. Then, quite recently, Murai [2] has shown that $T_{1}$ and $T_{2}$ are bounded on $L^{2}(R)$. On the other hand, as in our former paper [3], one can easily check that the kernels in the above singular integrals satisfy the desired conditions (3.1), (3.2) and (3.3) in [3]. Hence they are Calderón-Zygmund singular integral operators.

Finally we note that, because of the Calderón-Zygmund property, weighted norm inequalities hold for them, i.e., if $1<p<\infty$ and $w(x) \in A_{p}(\boldsymbol{R})$, then

$$
\left(\int_{-\infty}^{\infty}\left|T_{j} f(x)\right|^{p_{w}}(x) d x\right)^{1 / p} \leqq C(j, p)\left(\int_{-\infty}^{\infty}|f(x)|^{p} w(x) d x\right)^{1 / p},
$$

where $A_{p}(\boldsymbol{R})$ is the Muckenhoupt weight class $A_{p}$, (see, for example, [1] concerning $A_{p}$ ). (One can easily show that the arguments in Journé [1, pp. 47-58] hold in our case [3], too.)

Received February 10, 1984.

* Department of Mathematics, Ibaraki University, Mito, Ibaraki 310, Japan. 


\section{References}

[1] J-L. Journé, Calderón-Zygmund operators, Pseudo-differential operators and the Cauchy integral of Calderón, Lecture Notes in Math., No. 994, Springer Verlag, Berlin-Heidelberg, 1983.

[2] T. Murai, Boundedness of singular integral operators of Calderón type, II, Preprint series No. 1 Department of Mathematics, College of General Education, Nagoya University, 1983.

[ 3 ] K. Yabuta, Continuity of the mean values of BMO functions and Calderón-Zygmund properties of certain singular integrals, Bull. Fac. Sci., Ibaraki Univ., Math., No. 15 (1983), 1-8. 